\title{
Perception And Barriers Of Research Conduction Among Faculty Members Of BUMDC
}

\author{
Khalid Aziz, Abida Arif, Ghousia Shahid, Ayesha Afridi, Muhammad Faisal Fahim
}

ABSTRACT:

Objective: To identify the perception and barriers regarding research conduction among faculty members of BUMDC

Methodology: Descriptive cross sectional survey was conducted in Bahria University Medical and Dental College from June-September 2018. Participants both male and female with minimum one year of clinical/academic experience were included. Exclusion criteria were those faculty members not willing to participate and visiting faculty members.

Results: The response rate of this study was found to be 116/133 (87.21\%). Faculty members of MBBS were 74(63.8\%), BDS faculty 34(29.3\%) and DPT faculty 8 (6.9\%). Most difficult area of research was found to be statistical analysis 56 (48.3\%). Research is a important component of medical education $83(71.6 \%)$ respondents strongly agreed. I consider research as a part of long term career goals $55(47.4 \%)$ strongly agreed. Barriers were Lack of funding was strongly agreed by $44(37.9 \%)$. Lack of time was agreed by $49(42.2 \%)$ respondents and strongly agrees.

Conclusion: Perception of faculty was found to be positive regarding conduction of research. Majority of faculty members reported that research is an important part of medical education to enhance knowledge. Lack of funding, time and access to journal were found to be barriers in conducting research. Interest in research will develop if these barriers are minimized.

Key Words: Research, barriers, evidence based practice, medical faculty

\section{INTRODUCTION:}

Research in health care profession has a vital role in improving academic, clinical care facilities and administration ${ }^{1,2}$. Developing countries are lacking in the field of research due to different barriers in conducting research studies which ultimately leads to the dependency and reliance upon western ${ }^{3}$. Research is the main universal tool for health care professionals to groom their academic and clinical performances. The prospective of evidence based clinical and academic practices can be supplemented productively by the combine efforts and support of faculty members for each other ${ }^{4}$. Research skills enhances the critical thinking process of individuals ${ }^{5}$ previous studies have documented that due to lack of basic facilities, the interest

\begin{tabular}{|c|}
\hline $\begin{array}{l}\text { Khalid Aziz, } \\
\text { Vice Principal } \\
\text { Bahria University College of Physical Therapy } \\
\text { Email: vp.bucpt@bahria.edu.pk }\end{array}$ \\
\hline $\begin{array}{l}\text { Abida Arif, } \\
\text { Senior lecturer } \\
\text { Bahria University College of Physical Therapy }\end{array}$ \\
\hline $\begin{array}{l}\text { Ghousia Shahid, } \\
\text { Senior Lecturer } \\
\text { Bahria University College of Physical Therapy }\end{array}$ \\
\hline $\begin{array}{l}\text { Ayesha Afridi, } \\
\text { Lecturer } \\
\text { Bahria University College of Physical Therapy }\end{array}$ \\
\hline $\begin{array}{l}\text { Muhammad Faisal Fahim, } \\
\text { Researcher } \\
\text { Bahria University College of Physical Therapy }\end{array}$ \\
\hline $\begin{array}{l}\text { Received: } 01-10-18 \\
\text { Accepted: } 07-12-18\end{array}$ \\
\hline
\end{tabular}

level and practical applicability of research has declined ${ }^{3,6}$. There is prominent gap between research and actual practice and the reason for this gap is, the high pressure for more and more publications within a year and changes rigorrelevance framework criteria of journals which only favor rigor $^{7}$. Knowledge of evidence based practice while using different research methodologies in medical schools is very concomitant with post graduate research work and carrier development in medical academics. For this purpose many institutes are making policies and taking strong initiatives like mandatory tasks for students ${ }^{8}$.

Many health care seekers get unsuitable or even needless care for their major concerns without evidence based practice?. The idea of research based guidelines are positively reinforced by many health care professionals all over the world but practical implication is still far away in many setups ${ }^{10}$. Major issue faced by health care professionals while conducting a research is not enough time to produce quality research work in job timing ${ }^{11}$. Some barriers found for the conduction of research by the Promoting Action on Research Implementation in Health Services (PARIHS) model i.e. unable to statistically analyze the data, limited understanding of results from studies and their practical usability, unavailability of data sources to find evidence base ${ }^{12}$. While many other barriers are also present to be encounter by professionals for research ${ }^{13}$. These barriers can be categorized into personal barriers: which are related to individual's own knowledge, skills, and time management capabilities, inability to understand research methodology, results and its interpretation. Organizational barriers: which involve support, autonomy to implement change in health care on basis of evidence based practice. Cultural barriers: include unacceptance of established health care model in practical $^{14}$. 
New innovations or further investigation about already existing knowledge through the process of intellectual critical thinking comes in the domain of research activities ${ }^{15}$. Implementation of evidence based practices in relevant field is not possible without the support of institutional head, colleagues and staff members ${ }^{16}$. By conducting the questionnaire based survey among faculty members in out setup can identify the problems and barriers being faced by participants in conducting research. This might be helpful for smooth conduction of research studies.

\section{METHODOLOGY:}

Ethical clearance was received from Faculty Research Committee (FRC) \& Ethical Review Committee (ERC) for the study to be under taken in Bahria University Medical and Dental College (BUMDC) vide FRC letter \# FRCBUMDC 17/2018 \& ERC letter \# ERC 52/2018 respectively. The descriptive cross sectional survey was conducted from June-September 2018. 116 Participants both male and female with minimum one year of clinical/academic experience were included from medical (74), dental (34) and doctor of physical therapy section (8) (lecturer, Sr. Lecturer Assistant Professor, Associate Professor and Professor) with Non probability convenient sampling. Faculty members not willing to participate and Visiting faculty members were excluded from the study. The sample size was calculated through the prevalence of $50 \%$, confidence interval $95 \%$, $5 \%$ margin of error and expected population was 210 through the below mentioned formula.

$\mathrm{n}=\mathrm{N} * \mathrm{Z}^{2} * \mathrm{P}(1-\mathrm{P}) /\left[\mathrm{d}^{2} *(\mathrm{~N}-1)+\mathrm{Z}^{2} * \mathrm{P}(1-\mathrm{P})\right]$

$\mathrm{n}=210 *(1.96)^{2 *} 0.5(1-0.5) /\left[(0.05)^{2 *}(1.96)^{2 *} 0.5(1-0.5)\right]$

$\mathrm{n}=136$ (required sample)

A self-administered questionnaire with identity remained anonymous was distributed to faculty members of BUMDC from the post of lecturers up to professors. First part of the Questionnaire was based upon demographics and then thirteen questions were asked about perception of faculty members regarding research with likert scale responses of strongly agree to strongly disagree. These questions were taken after extensive literature search.

Second part of the questionnaire was based upon ten questions regarding barriers in conducting research and these questions were also taken from previous research work with same likert scale responses. some questions were added according to the local scenario of the institute. Questionnaires were collected back with response rate of $87.21 \%$ after a week of distribution. Those participants who did not respond within a week were given extra one week and then were reminded. As questionnaire was anonymous and full confidentiality was given to each participant without showing their name but the department has to be mentioned for comparison of results. Estimated time to complete the questionnaire was $10-15$ minutes.
Statistical analysis has been done on SPSS version 23.0. Frequency and percentages were calculated for all categorical variables. Bar/ Pie chart are made for different variables.

\section{RESULTS:}

The response rate of this study was found to be $116 / 136$ (85.29\%). Twenty questionnaires/ proforma were not filled and returned empty so these were excluded from data analysis. Faculty members of MBBS were 74(63.8\%), BDS faculty $34(29.3 \%)$ and DPT faculty $8(6.9 \%)$ respectively. Male to female ratio was $1: 3$ in which $29(25.0 \%)$ male and $87(75.0 \%)$ were female. senior lecturers participated were $45(38.8 \%)$, professors were $20(17.2 \%)$. Most of the faculty members $73(62.9 \%)$ were doing academic job. There were $97(83.6 \%)$ respondents who have conducted earlier researches. Most difficult area of research was found to be statistical analysis 56 (48.3\%). Most of the faculty involved was MBBS with Senior lecturer 25 whereas Professor and Lecturers were same 19. BDS faculty contains 17 senior lecturers and 11 lecturers. DPT faculty includes 4 lecturers and 3 senior lecturers and 1 assistant Professor. (Figure 1). Mostly the difficult area in research was Statistical analysis. There were 17 lecturers, 21 senior lecturers, 2 assistant professors, 7 associate professors and 9 Professors who mentioned statistical analysis is the difficult portion in research. Only two respondents told nothing is difficult in research. (Figure 2). Perception of research was asked in 13 questions from respondents. When asking about I consider research as important component of medical education 83 $(71.6 \%)$ respondents strongly agree followed by $23(19.8 \%)$ agree with this opinion. The question I am involved in research because it is mandatory 32 (27.6\%) strongly agreed followed by $37(31.9 \%)$ agreed while only $7(6.0 \%)$ strongly disagree. When asking about I have no interest in research $55(47.4 \%)$ disagreed the statement, 30 (25.9\%) strongly disagreed on it. The question I consider research as a part of long term career goals 55 (47.4\%) strongly agreed followed by $45(38.8 \%)$ agreed upon it. The question I think that BUMDC curriculum should have mandatory time for research 47 (40.5\%) strongly agreed and 39 (39.6\%) agreed upon it. When asking about I have adequate time in doing working hours to pursue research $41(35.3 \%)$ disagree while 12 $(10.3 \%)$ strongly disagree about time management. When asking about I receive adequate training in research methodology in medical college $31(26.7 \%)$ agree and only $12(10.3 \%)$ strongly agree on it. The question Research mentors are easily available to me was disagreed by 38 (32.8\%) whereas $28(24.1 \%)$ agreed upon it. When asking about Research supervisor's offer good training and guidance to me $34(29.3 \%)$ agree while neutral response were given by $41(35.3 \%)$ respondents. When asking about I have adequate opportunities to present research in medical college $43(37.1 \%)$ agreed and $12(10.3 \%)$ strongly agree on it. The question Appreciation and acknowledgment by higher authorities to do research is sufficient was agreed by 51 
$(44.0 \%)$ and strongly agree by $13(11.2 \%)$ respondents. When asking about I am doing Research because my peers are doing it $41(35.3 \%)$ disagree and 17 (14.7\%) strongly disagree on it. (Table 1). Questions regarding barriers of research were responded by all. Lack of funding was strongly agreed by $44(37.9 \%)$ and agreed by $41(35.3 \%)$ respondents. When asking about Lack of knowledge it was disagree by $36(31.0 \%)$ respondents whereas $31(26.7 \%)$ agree that they have dearth of knowledge regarding research. Lack of supervision was agreed by $39(33.6 \%)$ while disagreed by $23(19.8 \%)$ respondents. Lack of time was agreed by 49 (42.2\%) respondents and strongly agree by $25(21.6 \%)$. Lack of promotion/incentives was agreed by $37(31.9 \%)$ whereas disagree by $25(21.6 \%)$. When asking about Lack of access to journal 34 (29.3\%) agree with this opinion while $30(25.9 \%)$ responded disagree. When asking about Lack of free access to literature 34 (29.3\%) agreed and 32 (27.6\%) disagreed upon it. Lack of supports from colleagues was found in $25(21.6 \%)$ responded who agreed on it. Whereas 45 (38.8\%) found to be neutral. Lack of cooperation from participants was agreed by 39 (33.6\%) respondents and 27 (23.3\%) disagreed on it. Lack of cooperation from institution for data collection $30(25.9 \%)$ respondents agreed while 14 (12.1\%) strongly agree on it. (Table 2 )

\section{DISCUSSION:}

This study aimed to focus on perception about research and barriers regarding research conduction among faculty members of BUMDC, as research is an important component of present day health care system which cannot be ignored in either academic or clinical institutes. This topic can lead to understanding about important issues faced by researchers in form of barriers in institutes as a result; institutes can help themselves in providing better environment and facilities for future researchers.

In this study majority of the participants responded strongly agree on the fact that research is an important component of medical education, many of the participants perceive their higher interest in research and considering it the long term carrier goals for themselves which is positive aspect about awareness of the research and evidence based practice. Participant's perception about the time given for research is not adequate which should be considered by the institute.

Pager has reported in their study that research conduction in institutes is not likely to be done without faculty's interest in research and evidence based practice flourish the skills with development of self-confidence, self-satisfaction in doing their job and identifying the problems, clearing inquisitiveness of mind by answering the questions with research. ${ }^{18}$

Ghazzawi has stated that lack of time provision by institutes is an extrinsic factor organizational behavior for limitation of research practice because research is time taking activity, either a data collection part or searching and writing a literature. $^{19}$

Present study highlighted a very important intrinsic and predominantly extrinsic barriers faced by faculty members of institute which include lack of time for research at the top of the all barriers followed by lack of funding and promotion or incentives for practicing the evidence based practice. Participants agreed on the point that free access to journals and literature was lacking and making hurdles for researchers with low cooperation of research participants. Sabzwari has stated same findings in their study related to barriers of time allocation for research while on the other hand the lack of funding and incentives were considered least bothered barriers in research conduction ${ }^{20}$. Another study also reported the barriers to be lack of time, overburdened workload, and funding support for faculty members $^{21}$.

Research training of the faculty members is responsibility of medical education department of any institute, because participants perceived in present study with little or no training during medical college degree duration. While Raza has reported that research activity should be mandatory for medical colleges' curriculum for the professional

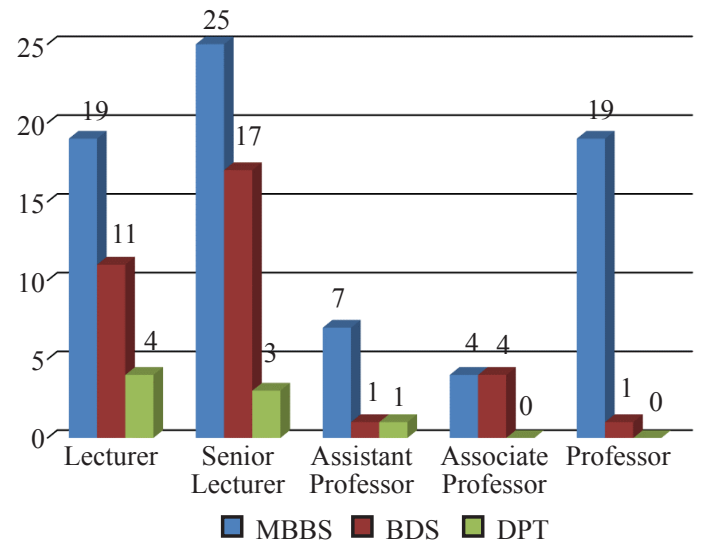

Figure 1: Disciplane wise Designations

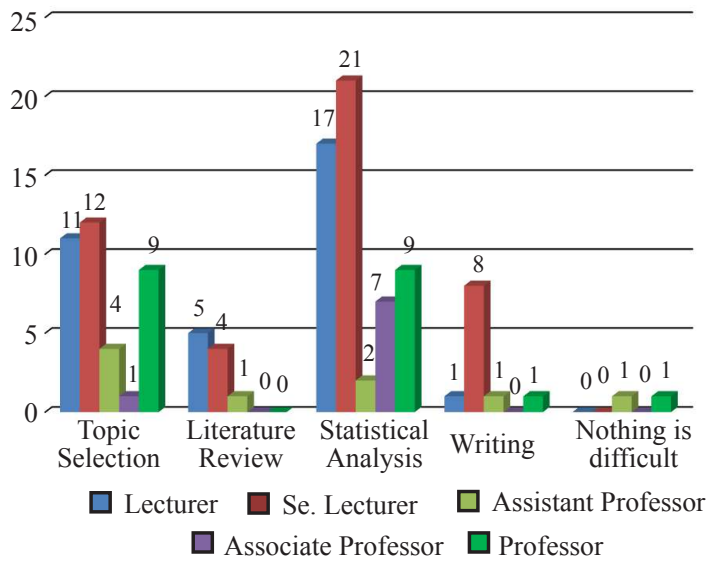

Figure 2: Difficult area in research in comparison of Designations 
Perception And Barriers Of Research Conduction Among Faculty Members Of BUMDC

\begin{tabular}{|c|c|c|c|c|c|}
\hline Items & $\begin{array}{l}\text { Strongly } \\
\text { Agree }\end{array}$ & Agree & Neutral & Disagree & $\begin{array}{l}\text { Strongly } \\
\text { Disagree }\end{array}$ \\
\hline $\begin{array}{l}\text { I consider research as important component of medical } \\
\text { education }\end{array}$ & $83(71.6 \%)$ & $23(19.8 \%)$ & $7(6.0 \%)$ & $3(20.6 \%)$ & 0 \\
\hline I am involved in research because it is mandatory & $32(27.6 \%)$ & $37(31.9 \%)$ & $22(19.0 \%)$ & $18(15.5 \%)$ & $7(6.0 \%)$ \\
\hline I have no interest in research. & $10(8.6 \%)$ & $7(6.0 \%)$ & $14(12.1 \%)$ & $55(47.4 \%)$ & $30(25.9 \%)$ \\
\hline I consider research as a part of long term career goals & $55(47.4 \%)$ & $45(38.8 \%)$ & $8(6.9 \%)$ & $5(4.3 \%)$ & $3(2.6 \%)$ \\
\hline $\begin{array}{l}\text { I think that BUMDC curriculum should have mandatory time } \\
\text { for research }\end{array}$ & $47(40.5 \%)$ & $39(33.6 \%)$ & $15(12.9 \%)$ & $11(9.5 \%)$ & $4(3.4 \%)$ \\
\hline I have adequate time in doing working hours to pursue research & $10(8.6 \%)$ & $29(25.0 \%)$ & $24(20.7 \%)$ & $41(35.3 \%)$ & $12(10.3 \%)$ \\
\hline $\begin{array}{l}\text { I receive adequate training in research methodology in medical } \\
\text { college }\end{array}$ & $12(10.3 \%)$ & $31(26.7 \%)$ & $24(20.7 \%)$ & $32(27.6 \%)$ & $17(14.7 \%)$ \\
\hline Research mentors are easily available to me & $11(9.5 \%)$ & $28(24.1 \%)$ & $28(24.1 \%)$ & $38(32.8 \%)$ & $11(9.5 \%)$ \\
\hline Research supervisors offer good training and guidance to me & $11(9.5 \%)$ & $34(29.3 \%)$ & $41(35.3 \%)$ & $22(19.0 \%)$ & $8(6.9 \%)$ \\
\hline $\begin{array}{l}\text { I have adequate opportunities to present research in medical } \\
\text { college. }\end{array}$ & $12(10.3 \%)$ & $43(37.1 \%)$ & $35(30.2 \%)$ & $18(15.5 \%)$ & $8(6.9 \%)$ \\
\hline $\begin{array}{l}\text { I have adequate opportunities to publish research during } \\
\text { medical college }\end{array}$ & $16(13.8 \%)$ & $42(36.2 \%)$ & $27(23.3 \%)$ & $23(19.8 \%)$ & $8(6.9 \%)$ \\
\hline $\begin{array}{l}\text { Appreciation and acknowledgment by higher authorities to } \\
\text { do research is sufficient. }\end{array}$ & $13(11.2 \%)$ & $51(44.0 \%)$ & $34(29.3 \%)$ & $12(10.3 \%)$ & $6(5.2 \%)$ \\
\hline I am doing Research because my peers are doing it. & $8(6.9 \%)$ & $33(28.4 \%)$ & $17(14.7 \%)$ & $41(35.3 \%)$ & $17(14.7 \%)$ \\
\hline
\end{tabular}

Table 1: Perception of Research

\begin{tabular}{|c|c|c|c|c|c|}
\hline Items & $\begin{array}{c}\text { Strongly } \\
\text { Agree }\end{array}$ & Agree & Neutral & Disagree & $\begin{array}{l}\text { Strongly } \\
\text { Disagree }\end{array}$ \\
\hline Lack of funding & $44(37.9 \%)$ & $41(35.3 \%)$ & $24(20.7 \%)$ & $6 \quad(5.2 \%)$ & $1 \quad(0.9 \%)$ \\
\hline Lack of knowledge & $5(4.3 \%)$ & $31(26.7 \%)$ & $24(20.7 \%)$ & $36(31.0 \%)$ & $20(17.2 \%)$ \\
\hline Lack of supervision & $16(13.8 \%)$ & $39(33.6 \%)$ & $22(19.0 \%)$ & $23(19.8 \%)$ & $16(13.8 \%)$ \\
\hline Lack of time & $25(21.6 \%)$ & $49(42.2 \%)$ & $25(21.6 \%)$ & $10(8.6 \%)$ & $7(6.0 \%)$ \\
\hline Lack of promotion/incentives & $21(18.1 \%)$ & $37(31.9 \%)$ & $23(19.8 \%)$ & $25(21.6 \%)$ & $10(8.6 \%)$ \\
\hline Lack of access to journal & $12(10.3 \%)$ & $34(29.3 \%)$ & $25(21.6 \%)$ & $30(25.9 \%)$ & $15(12.9 \%)$ \\
\hline Lack of free access to literature & $19(16.4 \%)$ & $34(29.3 \%)$ & $20(17.2 \%)$ & $32(27.6 \%)$ & $11(9.5 \%)$ \\
\hline Lack of supports from colleagues & $7(6.0 \%)$ & $25(21.6 \%)$ & $45(38.8 \%)$ & $30(25.9 \%)$ & $9(7.8 \%)$ \\
\hline Lack of cooperation from participants & $9 \quad(7.8 \%)$ & $39(33.6 \%)$ & $32(27.6 \%)$ & $27(23.3 \%)$ & $9(7.8 \%)$ \\
\hline Lack of cooperation from institution for data collection & $14(12.1 \%)$ & $30(25.9 \%)$ & $35(30.2 \%)$ & $27(23.3 \%)$ & $10(8.6 \%)$ \\
\hline
\end{tabular}

Table 2: Barriers of Research

development ${ }^{3}$. Statistical analysis of the research is considered to be the most difficult and technical part of research conduction among the faculty members of BUMDC, other studies reported the same preferences about barriers while statistical analysis to be one of the top five barriers in research conduction $^{22,23}$.
Duncan has reported in their study that lack of financial funding and medical research methodology knowledge are leading to the least interest of faculty members in conducting research ${ }^{24}$.

The barriers faced by the faculty members in data collection 
process is also considered to be the most bothersome barrier which is due to the lack of cooperation by sample individuals either rejecting to participate in research or wrong answers to the questions asked by researcher ${ }^{25}$.

\section{CONCLUSION:}

Perception of faculty regarding conduction of research was found to be positive. Mostly faculty members reported that it is an important part of medical education to enhance knowledge. They consider research as a part of long term career goals. However, Lack of funding, time and access to journal were found to be the main barriers in conducting research. Interest in research will develop if barriers are removed from the pathway or even if they are minimized.

\section{REFERENCES:}

1. Rizvi NF, Gulzar S, Nicholas W, Nkoroi B. Barriers in adopting blended learning in a private university of Pakistan and East Africa: faculty members' perspective. mHealth. 2017; 3 (18): $1-7$

2. Grobgeld E, Teichman-Weinberg A, Wasserman E, Barchilon Ben-Av M. Role perception among faculty members at teacher education colleges. Australian Journal of Teacher Education. 2016; 41(5): 78-98

3. Raza F. Nisa Q. Perception, attitudes and barriers in undergraduate medical students toward medical research at rehman medical college, peshawar, pakistan. Khyber Medical University Journal, 2017; 9(3):146-149

4. Chevan J. Mkumbuzi VR. Biraguma J. Culture, language, and resources: overcoming barriers to research collaboration with physical therapist education program faculty in a developing country. Journal of Physical Therapy Education, 2012; 26(1): 50-54.

5. Aquino AB, Ramos NP, Nolasco CJ. Faculty Perceptions, Skills and Problems on Assessment in Undergraduate Programs in a State University Extension Campus in the Philippines. Asia Pacific Journal of Multidisciplinary Research, 2015; 3(3): 39-51.

6. Shuva NZ, Taisir R. Faculty members perceptions and use of open access journals: Bangladesh perspective. IFLA journal. 2016; 42(1): 36-48.

7. Bager T. Knowledge exchange and management research: barriers and potentials. European Business Review. 2018; 30(2): 169-182.

8. AlGhamdi KM, Moussa NA, AlEssa DS, AlOthimeen N, AlSaud AS. Perceptions, attitudes and practices toward research among senior medical students. Saudi Pharmaceutical Journal. 2014; 22(2):113-7.

9. Grol R, Grimshaw J. From best evidence to best practice: effective implementation of change in patients' care. The lancet. 2003; 362 (9391): 1225-1230.

10. Leatherman ST, Hibbard JH, McGlynn EA. A research agenda to advance quality measurement and improvement. Medical care. 2003; 41(1): 80-86.

11. Sarabia-Cobo CM, Sarabia-Cobo AB, Pérez V, Hermosilla $\mathrm{C}$, Nuñez MJ, de Lorena P. Barriers in implementing research among registered nurses working in the care of the elderly: a multicenter study in Spain. Applied Nursing Research. 2015; 28(4):352-5.

12. Janssen J, Hale L, Mirfin-Veitch B, Harland T. Perceptions of physiotherapists towards research: a mixed methods study. Physiotherapy. 2016; 102(2):210-6.

13. Memon AR, Rathore FA. The Rising Menace of Predatory Publishing: Terms, Concepts, and Suggestions for Pakistani Researchers. J Coll Physicians Surg Pak. 2018; 28(8): 579580 .

14. Srijana KC, Subramaniam PR, Paudel S. Barriers and Facilitators of Utilizing Research Among Nurses in Nepal. The Journal of Continuing Education in Nursing. 2016; 47(4):171-9.

15. Jusoh R, Abidin ZZ. The Teaching-Research Nexus: A Study on the Students' Awareness, Experiences and Perceptions of Research. Procedia-Social and Behavioral Sciences. 2012; 38: 141-8.

16. Williams B, Perillo S, Brown T. What are the factors of organisational culture in health care settings that act as barriers to the implementation of evidence-based practice? A scoping review. Nurse education today. 2015; 35(2):e34-41.

17. Malik AN, Anwar S, Siddiqi FA. Research Barriers \& facilitators of Physical Therapists of Pakistan. Rawal Medical Journal. 2016; 41(3): 369-72.

18. Pager S, Holden L, Golenko X. Motivators, enablers, and barriers to building allied health research capacity. Journal of Multidisciplinary Healthcare. 2012; 5:53-59

19. Ghazzawi I. Job satisfaction antecedents and consequences: A new conceptual framework and research agenda. The Business Review. 2008; 11(2): 1-10.

20. Sabzwari S, Kauser S, Khuwaja AK. Experiences, attitudes and barriers towards research amongst junior faculty of Pakistani medical universities. BMC medical education. 2009; 9(1): 68-72.

21. Wenke RJ, Mickan S, Bisset L. A cross sectional observational study of research activity of allied health teams: is there a link with self-reported success, motivators and barriers to undertaking research? BMC health services research. 2017; 17(1): 114-118.

22. Brown CE, Wickline MA, Ecoff L, Glaser D. Nursing practice, knowledge, attitudes and perceived barriers to evidence-based practice at an academic medical center. Journal of advanced nursing. $2009 \mathrm{Feb} ; 65(2): 371-81$.

23. Hutchinson AM, Johnston L. Bridging the divide: a survey of nurses' opinions regarding barriers to, and facilitators of, research utilization in the practice setting. Journal of clinical nursing. 2004;13(3):304-15.

24. Duncan EA, Murray J. The barriers and facilitators to routine outcome measurement by allied health professionals in practice: a systematic review. BMC health services research. 2012;12(1):96.

25. Parahoo K, McCaughan EM. Research utilization among medical and surgical nurses: a comparison of their self reports and perceptions of barriers and facilitators. Journal of nursing management. 2001;9(1):21-30. 